This item is the archived peer-reviewed author-version of:

\title{
Airborne-induced lymphomatoid contact dermatitis caused by methylisothiazolinone
}

\section{Reference:}

Van Steenkiste Eva, Goossens An, Meert Hans, Apers Sandra, Aerts Olivier.- Airborne-induced lymphomatoid contact dermatitis caused by methylisothiazolinone

Contact dermatitis - ISSN 0105-1873 - 72:4(2015), p. 237-240

Full text (Publishers DOI): http://dx.doi.org/doi:10.1111/cod.12359

To cite this reference: http://hdl.handle.net/10067/1243110151162165141 


\title{
Airborne-induced lymphomatoid contact dermatitis caused by methylisothiazolinone
}

\author{
Eva Van Steenkiste ${ }^{1}$, An Goossens ${ }^{1}$, Hans Meert ${ }^{2}$, Sandra Apers ${ }^{2}$ and Olivier Aerts ${ }^{3}$ \\ ${ }^{1}$ Department of Dermatology, University Hospitals, K.U. Leuven, B-3000 Leuven, Belgium, ${ }^{2}$ Research Group Natural Products and Food - Research and \\ Analysis (NatuRA), Department of Pharmaceutical Sciences, University of Antwerp, B-2650, Antwerp, Belgium, and ${ }^{3}$ Department of Dermatology, University \\ Hospital Antwerp, B-2650 Antwerp, Belgium \\ doi:10.1111/cod.12359
}

Key words: airborne; allergic contact dermatitis; cosmetics; detergent; lymphomatoid; methylisothiazolinone; non-eczematous; patch testing; preservative; skin biopsy.

Methylisothiazolinone (MI) is, in Belgium (1) and elsewhere, now an extremely frequent cause of allergic contact dermatitis $(\mathrm{ACD})$, owing to its presence in cosmetics and paints, in particular, but also in detergents. Allergic contact reactions are primarily eczematous skin reactions, but occasionally may present as non-eczematous eruptions (2), such as erythema multiforme-like, lichen planus-like or lymphomatoid reactions; this may lead to a delay in reaching the correct diagnosis. Here, we present the case of a woman who had experienced face and neck dermatitis for several years, and who presented with a lymphomatoid eruption for which MI was determined to be the contact allergen that was primarily responsible.

\section{Case Report}

A 58-year-old non-atopic woman presented to our clinic in Leuven in June 2013 with an eruption on the face and neck that had started a few years earlier with erythematous patches around her eyes. Multiple treatments had been administered, that is, several corticosteroid creams, and topical and systemic antibiotics. She had also applied several cosmetic products, and noticed exacerbation when she was exposed to sunlight or when she applied sunscreens. A diagnosis of peri-ocular dermatitis, caused by the repeated application of different topical corticosteroids, had been suggested, for which she had been prescribed several bland moisturizers. The rash,

Correspondence: An Goossens, Contact Allergy Unit, Department of Dermatology, University Hospitals St-Raphael - K.U. Leuven, Kapucijnenvoer 33, B-3000 Leuven, Belgium. Tel: +32 1633 78 70; Fax: +32 163378 72. E-mail: an.goossens@uzleuven.be

Conflicts of interest: The authors declare no conflict of interests. however, had progressively spread to the rest of her face, retro-auricular area, and neck, and a few weeks before she consulted us, the dermatitis had also involved the forehead and hairline at the temples.

Patch tests had been performed elsewhere, presumably only with the European baseline series, and reported as negative. When she was first seen by us, examination showed erythematous and urticarial patches on her forehead and neck, with some desquamation (Figs. 1 and 2). Differential diagnoses included eczema, ACD, Jessner's lymphocytic infiltrate, lupus erythematosus, granuloma annulare, mycosis fungoides, lymphoma, and erythema annulare centrifugum. A skin biopsy showed discrete spongiosis and parakeratosis, and a limited lymphocytic and plasmocytic perivascular infiltrate in the upper dermis; this was interpreted as chronic eczema. We prescribed a topical corticosteroid, and the patient was advised to use a moisturizing cream and shampoo free of important allergens, including isothiazolinones.

Patch testing was again performed, with IQ Ultra chambers (Chemotechnique Diagnostics, Vellinge, Sweden) covered with Mefix (Mölnlycke Health Care, Göteborg, Sweden), with readings at D2 and D4, with the European baseline series (including benzisothiazolinone $0.05 \%$ pet. and octylisothiazolinone 0.1 pet., both from Chemotechnique Diagnostics), a cosmetic series, and her own products, along with the ingredients. Positive reactions were observed to MI 2000 ppm aq. only, whereas MI $500 \mathrm{ppm}$ aq. and methylchloroisothiazolinone (MCI)/MI $100 \mathrm{ppm}$ aq. gave negative results; the patients also reacted to alkyl glucosides, panthenol, and several cosmetic products that she had brought with her (Table 1).

At the time of consultation, MI was identified in only one of the products that the patient had previously 


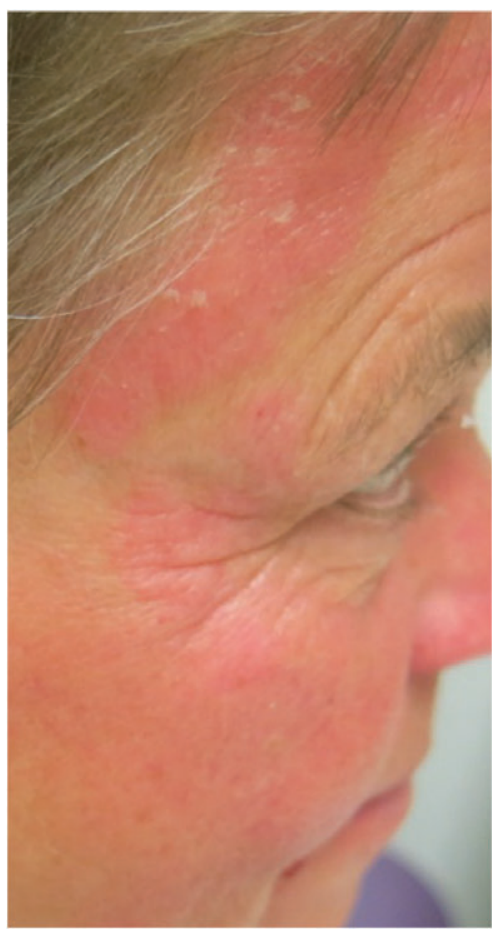

Fig. 1. Airborne 'lymphomatoid' contact dermatitis on the face caused by a methylisothiazolinone-containing floor detergent.

used, that is, Topialyse Palpebral ${ }^{\circledR}$ (SVR, Le Plessis-Pâté, France), from which MI has recently been removed; however, she mentioned having applied numerous other cosmetic products with unknown composition to which she had been intolerant and that she had discarded.

Decyl glucoside was found in the sunscreen product (Roc ${ }^{\circledR}$ Soleil protection), and panthenol was a constituent of Roc Calmance intolerance repairing cream and soothing moisturizer (Johnson \& Johnson Consumer France S.A.S., Issy-les-Moulineaux, France), and of Kneipp ${ }^{\circledR}$ body lotion (Kneipp-Werke, Würzburg, Germany); all produced positive patch test reactions when tested 'as is'.

Notwithstanding discontinuation of the suspect cosmetic products, the eczematous lesions persisted in the face and neck, and deteriorated each time that the floors of her house had been cleaned with a particular detergent. Analysis at the Antwerp laboratory with high-performance liquid chromatography with an ultraviolet detector showed the presence of MI and benzisothiazolinone (BIT) in the detergent at concentrations of 181.3 and $4.6 \mathrm{ppm}$ (mean of three independent results), respectively. A spike experiment confirmed the suitability of the applied method for this sample, resulting in recovery rates of $96.9 \%$ and $97.5 \%$ for MI and BIT, respectively. Her dermatitis was now considered to be

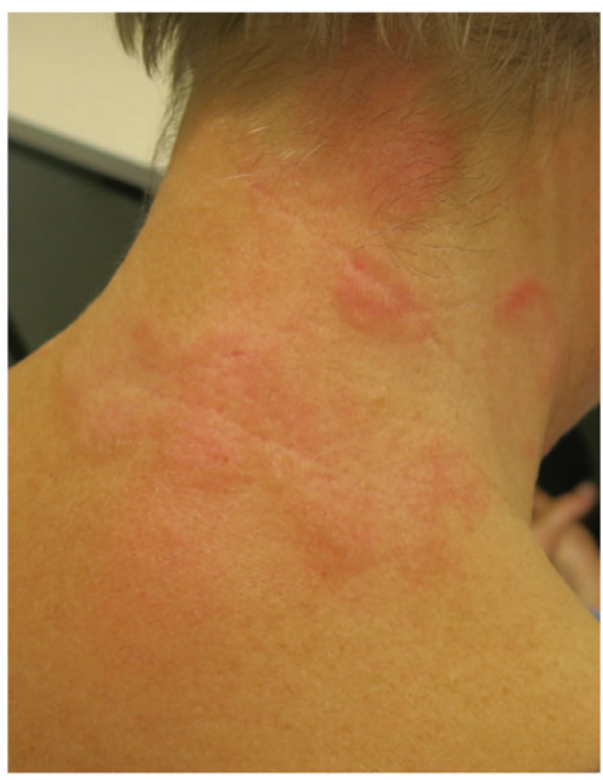

Fig. 2. Similar lesions to those in Fig. 1 on the neck.

airborne-induced, possibly favoured by the underfloor heating system. Since avoiding this cleaning agent, she has remained completely free of symptoms.

\section{Discussion}

Skin exposure to high concentrations of both MCI/MI and MI can cause severe chemical burns (3, 4), which may be followed by primary sensitization (4). Contact allergy to MI usually presents as eczematous lesions, very often on the face, with frequent involvement of the eyelids, and is

Table 1. Positive patch test reactions

\begin{tabular}{|c|c|c|}
\hline & D2 & D4 \\
\hline \multicolumn{3}{|l|}{ European baseline series } \\
\hline Methylisothiazolinone 2000 ppm* & - & + \\
\hline \multicolumn{3}{|l|}{ Cosmetic series } \\
\hline Decyl glucoside 5\% pet. ${ }^{\dagger}$ & $+?$ & + \\
\hline Lauryl glucoside $3 \%$ pet. & - & + \\
\hline Panthenol 5\% pet. ${ }^{\S}$ & $+?$ & + \\
\hline \multicolumn{3}{|l|}{ Own cosmetics (tested 'as is') } \\
\hline SVR ${ }^{\circledast}$ Topialyse Palpebral & + & + \\
\hline Kneipp ${ }^{\circledast}$ body lotion & + & + \\
\hline Roc $^{\circledast}$ Soleil protection haute SPF 50 & - & + \\
\hline Roc ${ }^{\circledast}$ Calmance soothing moisturizer & - & + \\
\hline Roc $^{\circledast}$ Calmance intolerance repairing & - & + \\
\hline
\end{tabular}

* Obtained from Malmö Hospital, Department of Occupational Dermatology, Malmö, Sweden.

${ }^{\dagger}$ Allergeaze $^{\mathrm{TM}}$, Brial Allergen GmbH, Greven, Germany.

${ }^{\ddagger}$ Chemotechnique Diagnostics, Vellinge, Sweden.

$\S_{\text {Trolab }}{ }^{\mathrm{TM}}$, Almirall Hermal, Reinbek, Germany. 
often accompanied by complaints of burning and severe swelling, a mixed eczematous-urticarial skin eruption (1), or on the hands, where it can present as chronic eczema. It may also mimic other eczematous reactions, such as seborrhoeic, asteatotic (1), photo-allergic (5) and atopic dermatitis, particularly in widespread reactions such as in cases of airborne exposure $(1,5,6)$. The lesions may also be lichenified and infiltrated, with follicular accentuation, or present as sharply delineated plaques, and can even be photo-aggravated (1). Moreover, contact-allergic reactions to isothiazolinones can be non-eczematous and may mimic, both clinically and histologically, subacute or chronic discoid lupus erythematosus, or lymphocytic infiltration, as was previously described for MCI/MI by Morren et al. in 1992 (5) and Mendese et al. in 2010 (7), and just recently also by Knackstedt and Zug (8).

MI allergy may also be mistaken for a drug eruption (1). Moreover, Gebhardt et al. described a case of generalized (airborne) urticaria following exposure to wall paints (9), and, recently, a case of genital dermatitis causing relapsing episodes of bacterial cellulitis (1) and a contact dermatitis masquerading as folliculitis decalvans induced by a hair gel have also been reported (10).

Unusual presentations of contact allergy have been described for other allergens as well, for example an erythema multiforme-like eruption caused by primula (11), and erythema multiforme-like contact dermatitis and pigmented and purpuric contact dermatitis caused by textile dyes (12). Also, $p$-phenylenediamine has been held responsible for inducing atypical allergic contact reactions, even resembling Sweet's syndrome (13), whereas repeated biopsies showed lymphomatoid dermatitis. Sometimes, dense lymphocytic infiltrates may cause the dermatologist to erroneously consider the patient as having cutaneous T-cell lymphoma (mycosis fungoides), as has been reported for strong allergens such as dimethyl fumarate (14).

Finally, respiratory symptoms induced by isothiazolinones may also occur (15-17).

\section{Conclusion}

In cases with an unusual clinical presentation, an allergic contact reaction may not always be suspected, and the possibility of ACD may then only be considered during follow-up, when patients do not respond to treatment initiated for an erroneous diagnosis. This underlines the importance of performing a skin biopsy and, importantly, the correct interpretation of it. In our case, the patient presented with longstanding erythematous, infiltrated and urticarial patches, along with scaling, on her forehead and neck that proved to be resistant to therapy. On the basis of the clinical presentation, we initially discussed a broad scope of differential diagnoses, including ACD, and considered it to be the most likely diagnosis when interpretation of the skin biopsy was compatible with chronic eczema showing, however, marked lymphocytic infiltrates. The diagnosis of ACD was then finally confirmed when patch tests showed the relevant allergens, although it should be mentioned that the underlying contact allergy to MI was not shown by the previous patch tests, but could only be detected with the $2000 \mathrm{ppm}$ patch test concentration, as now recommended (18); however, for MCI/MI, 200 ppm has been recommended (19). Adequate test concentrations in patch testing might prevent patients from suffering from skin disease for several years, as in this case.

\section{References}

1 Aerts $\mathrm{O}$, Baeck M, Constandt L et al. The dramatic increase in the rate of methylisothiazolinone contact allergy in Belgium: a multicentre study. Contact Dermatitis 2014: 71: 41-48.

2 Goon A, C-L Goh. Non-eczematous contact reactions. In: Contact Dermatitis, 5 th edition, Duus Johansen J, Peter J, Frosch P J, Lepoittevin J-P (eds): Berlin, Heidelberg, Springer-Verlag, 2012: pp. 415-427.

3 Bayraktar A, Ozcan M. An unusual case: burn following an accidental exposure to methylchloroisothiazolinone/ methylisothiazolinone. J Burn Care Res 2007: 28: 195-197.

4 Isaksson M, Gruvberger B, Bruze M. Occupational contact allergy and dermatitis from methylisothiazolinone after contact with wall covering glue and after a chemical burn from a biocide. Dermatitis 2004: 15: 201-205.

5 Morren M A, Dooms-Goossens A, Delabie J, De Wolf-Peeters C, Mariën K, Degreef H. Contact allergy to isothiazolinone derivatives: unusual clinical presentations. Dermatology 1992: 184: 260-264.

6 Aerts O, Cattaert N, Lambert J, Goossens A. Airborne and systemic dermatitis, mimicking atopic dermatitis, caused by methylisothiazolinone in a young child. Contact Dermatitis 2013: 68: 250-256.

7 Mendese G, Beckford A, Demierre M F. Lymphomatoid contact dermatitis to baby wipes. Arch Dermatol 2010: 146 934-935.

8 Knackstedt T J, Zug K A. T-cell lymphomatoid contact dermatitis: a challenging case and review of the literature. Contact Dermatitis 2014: doi:10.1111/cod.12294.

9 Gebhardt M, Looks A, Hipler U C. Urticaria caused by Type IV sensitization to isothiazolinones. Contact Dermatitis 1997: 36: 314.

10 Aerts O, Van Dyck F, Dandelooy J, Mellaerts T, Lambert J. Contact dermatitis masquerading as folliculitis decalvans: methylisothiazolinone strikes again!. Dermatitis 2014: 25: 276.

11 Lengrand F, Tellart A S, Segard M, Dejobert Y, Thomas P. Erythema 
LYMPHOMATOID DERMATITIS CAUSED BY METHYLISOTHIAZOLINONE • VAN STEENKISTE ET AL.

multiforme-like eruption: an unusual presentation of primula contact allergy. Contact Dermatitis 2001: 44: 35.

12 Lazarov A, Cordoba M, Plosk N, Abraham D. Atypical and unusual clinical manifestations of contact dermatitis to clothing (textile contact dermatitis): case presentation and review of the literature. Dermatol Online J 2003: 9: 1.

13 Veysey E C, Burge S, Cooper S. Consort contact dermatitis to paraphenylenediamine, with an unusual clinical presentation of tumid plaques. Contact Dermatitis 2007: 56: 366-367.

14 Susitaival P, Winhoven S M, Williams J et al. An outbreak of furniture related dermatitis ('sofa dermatitis') in Finland and the UK: history and clinical cases. J
Eur Acad Dermatol Venereol 2010: 24: 486-489.

15 Lundov M D, Mosbech H, Thyssen J P et al. Two cases of airborne allergic contact dermatitis caused by methylisothiazolinone in paint. Contact Dermatitis 2011: 65: 176-179.

16 Bohn S, Niederer M, Brehm K et al. Airborne contact dermatitis from methylchloroisothiazolinone in wall paint. Abolition of symptoms by chemical allergen inactivation. Contact Dermatitis 2000: 42: 196-201.

17 Lundov M D, Friis U F, Menné T et al. Methylisothiazolinone in paint forces a patient out of her apartment. Contact Dermatitis 2013: 69: 251-259.
18 Bruze M, Engfeldt M, Gonçalo M et al. Recommendation to include methylisothiazolinone in the European baseline patch test series - on behalf of the European Society of Contact Dermatitis and the European Environmental and Contact Dermatitis Research Group. Contact Dermatitis 2013: 69: 263-270.

19 Bruze M, Goossens A, Isaksson M. Recommendation to increase the test concentration of methylchloroisothiazolinone/methylisothiazolinone in the European baseline patch test series - on behalf of the European Society of Contact Dermatitis and the European Environmental and Contact Dermatitis Research Group. Contact Dermatitis 2014: 71: $35-40$. 